\title{
Práticas profissionais dos professores de Matemática
}

\author{
Joao Pedro da Ponte; Marisa Quaresma e Neusa Branco \\ Instituto de Educação da Universidade de Lisboa (Portugal)
}

Recibido el 20 de julio de 2011; aceptado el 2 de septiembre de 2011

\section{Prácticas profesionales de los profesores de Matemáticas}

\section{Resumen}

Este artículo discute la noción de práctica, a partir del análisis del trabajo de un profesor de aula. Comienza analizando dos perspectivas de esta noción: cognitivista y sociocultural, con especial atención para las prácticas profesionales de los profesores. Identifica dos elementos claves de estas prácticas: las tareas y el discurso del aula. Seguidamente, considera dos prácticas en el proceso de enseñanzaaprendizaje de la Matemática, la presentación de las tareas a los alumnos y las discusiones colectivas, que se problematizan, ilustrándolas con episodios de $5^{\circ}$ y $7^{\circ}$ año. El artículo termina con una presentación de un modelo para el estudio de las prácticas profesionales de los profesores de matemáticas.

Palabras Claves. Prácticas profesionales, enseñanza de la matemática, tareas, discurso, curriculum.

\section{Práticas profissionais dos professores de Matemática}

\section{Resumo}

Este artigo discute a noção de prática tendo em vista analisar o trabalho do professor na sala de aula. Começa por analisar duas abordagens desta noção, a cognitivista e a sociocultural, com especial atenção para as práticas profissionais dos professores, e identifica dois elementos-chave destas práticas: as tarefas e o discurso na sala de aula. De seguida, debruça-se sobre duas práticas no processo de ensino-aprendizagem da Matemática, a apresentação das tarefas aos alunos e as discussões coletivas, que problematiza, ilustrando-as com episódios de aula do $5^{\circ}$ e do $7 .^{\circ}$ ano. O artigo encerra com a apresentação de elementos de um modelo para o estudo das práticas profissionais dos professores de Matemática.

Palavras-chave. Práticas profissionais, ensino da matemática, tarefas, discurso, currículo.

\section{Professional practices of Mathematics teachers}

\section{Abstract}

This article discusses the notion of practice in order to analyze the work of the teacher in the classroom. It begins by examining two approaches for this notion, the cognitive and the socio-cultural, with special attention to the professional practices of the teachers, and identifies two key elements of such practice: the tasks and the classroom discourse. It then focuses on two practices in the teaching and learning of mathematics, the presentation of tasks to students and the collective discussions, reviewing the main features and issues and illustrating them with episodes of the grades 5 and 7 classrooms. The

Para citar: Ponte, J. P., Quaresma, M. e Branco, N. (2012). Práticas profissionais dos professores de Matemática. Avances de Investigación en Educación Matemática, 1, 65-86. 
article ends with the presentation of elements for a model to study the professional practices of mathematics teachers.

Key-words. Professional practices, mathematics teaching, tasks, discourse, curriculum.

\section{Pratiques professionnelles des maîtres de Mathématiques ${ }^{1}$}

\section{Résumé}

Cet article discute la notion de pratique en vue d'analyser le travail du professeur dans la classe. Il commence par examiner deux approches à cette notion, la cognitive et la socio culturelle avec une attention spéciale aux pratiques professionnelles des professeurs, et on identifie deux éléments clés de ces pratiques: les tâches et les discours dans la salle de classe. Il se centre ensuite sur deux pratiques dans le processus d'enseignement et d'apprentissage des Mathématiques, la présentation des taches aux étudiants et les discussions collectives, tout en soulignant les principales caractéristiques illustrées par des épisodes de classe des 5ème et 7ème années. L'article finit avec la présentation d'un modèle qui permet étudier les pratiques professionnelles des professeurs de Mathématiques.

Paroles clés. Pratiques professionnelles, enseignement des mathématiques, tâches, discours, curriculum.

É largamente reconhecido que o professor desempenha um papel essencial no processo de ensino-aprendizagem. Mais do que aquilo que o professor sabe, o essencial é o modo como ele atua na sala de aula. $\mathrm{Na}$ verdade, o professor pode ter muito conhecimento de Matemática e de Educação e, no seu ensino, não tirar todo o partido dele. Isto não significa que estes aspetos não sejam importantes - significa apenas que é necessário estudá-los tendo em atenção o que acontece na prática profissional do professor. Este artigo pretende dar um contributo para a compreensão das práticas profissionais dos professores de Matemática, tendo como pano de fundo os debates curriculares atuais.

A análise dos trabalhos realizados ao longo de 30 anos no Psychology of Mathematic Education (PME), mostra que, ao estudar o professor, num primeiro momento, se começou por dar atenção aos seus conhecimentos e crenças, para, num segundo momento, se trazer para o primeiro plano as práticas profissionais (Ponte \& Chapman, 2006). No entanto, ainda hoje, o conceito de prática permanece algo indefinido, sendo muito frequentemente tomado como sinónimo de "ação". É o que acontece quando se diz que as práticas são "aquilo que os professores fazem". Esta posição está presente, por exemplo, numa revisão recente de Sánchez (2011), quando afirma que "os investigadores desta área tentam caracterizar as ações que os professores realizam dentro da sala de aula" (p. 134).

Neste artigo discutimos a noção de prática tendo em vista analisar o trabalho do professor na sala de aula. Começamos por analisar algumas abordagens desta noção, com especial atenção para as práticas profissionais dos professores. De seguida, debruçamo-nos sobre algumas práticas-chave no processo de ensino-aprendizagem da Matemática, a apresentação das tarefas aos alunos e as discussões coletivas. Encerramos

\footnotetext{
${ }^{1}$ Este trabalho é financiado por fundos nacionais através da FCT - Fundação para a Ciência e Tecnologia no âmbito do Projeto Práticas Profissionais dos Professores de Matemática (contrato PTDC/CPECED/0989311/2008). Os autores agradecem os comentários detalhados de Isabel Velez e Joana Mata Pereira a versões preliminares deste artigo bem como aos membros da equipa do projeto que participaram nas discussões sobre este tema.
} 
com uma síntese com diversas sugestões para o estudo das práticas profissionais dos professores.

\section{O conceito de prática profissional}

Como referimos, o conceito de prática é muito usado na literatura de educação matemática, assumindo sentidos diversos, mas, grande parte das vezes, com reduzida precisão conceptual. Nesta seção analisamos diversas abordagens teóricas para o estudo das práticas e fazemos uma breve caracterização dos domínios das práticas profissionais dos professores e dos diversos sentidos (ou níveis) em que se fala destas práticas.

\subsection{Abordagem cognitivista}

Tendo por base uma perspetiva de Psicologia Cognitiva, Leinhardt (1988) empreendeu diversos estudos nos anos de 1980 sobre o trabalho do professor na sala de aula recorrendo a conceitos como "guião curricular", "rotina" e "agenda". Mais recentemente, numa perspetiva teórica semelhante, Schoenfeld (2000) propôs um modelo para o estudo do processo de ensino do professor, em que o centro da atenção está nas decisões e ações que este assume na sua prática e que o autor procura explicar tendo por base o conhecimento, as crenças e os objetivos do docente.

Este modelo apoia-se na literatura de diversas áreas, incluindo os campos da tutoria de sistemas inteligentes, da inteligência artificial e dos estudos sobre "fatores humanos". Atende também aos estudos sobre o conhecimento profissional do professor, incluindo os trabalhos de Leinhardt e também os estudos sobre o conhecimento e crenças do professor, em especial os apoiados na noção de "conhecimento pedagógico do conteúdo" de Shulman (1986).

O autor indica que, na sua perspetiva, o modelo não é avaliativo, isto é, não privilegia nenhum tipo de ensino em relação a qualquer outro. Além disso, considera que o seu modelo pode ser usado em diversas escalas, desde a planificação anual e mensal até à aula, segmento de aula e micro episódio de interação professor-aluno. $\mathrm{O}$ modelo procura ter em atenção o modo como o professor toma decisões, atendendo às prioridades que estabelece e aos planos de ação que formula, e atende também ao modo como estes planos são depois concretizados ou não em sequências de ação. A ilustrar as suas ideias, apresenta o que se podem considerar duas práticas profissionais, a exposiçãoe a conversa simples.

Even e Schwartz (2002) apresentam uma análise de uma aula, que designam de "análise cognitiva", e que se enquadra nesta perspetiva. Esta análise tem por base a caracterização das formas de resposta que um professor dá durante a realização de uma determinada tarefa: (i) acompanhamento, (ii) elaboração, (iii) oposição, (iv) confusão, e (v) ausência de resposta. Esta análise, no fundo, caracteriza o discurso do professor, sendo comparável a tipologias sobre o questionamento, como a que distingue diversos tipos de perguntas a que o professor pode recorrer durante a aula (nomeadamente, perguntas de teste, focalização e inquirição). Note-se que, recolhendo elementos pontuais, fazendo médias e calculando outras estatísticas, é possível obter um quadro global da aula a partir deste tipo de abordagem. 


\subsection{Abordagem sociocultural}

A maioria dos autores que aborda o conceito de prática profissional numa perspetiva sociocultural tem subjacente, de um modo ou de outro, a teoria da atividade. Even e Schwartz (2002) dizem que "atividades são cadeias de ações relacionadas pelo mesmo objeto e pelo mesmo motivo" (p. 341). O objeto da atividade é a realização de uma certa tarefa e o motivo é o conjunto de razões que leva um dado indivíduo a realizar essa tarefa. Temos então três elementos principais numa atividade: (i) as ações, que são os componentes básicos da atividade, apenas compreensíveis no quadro dessa atividade e que devem ser distinguidas das operações específicas através das quais se concretizam; (ii) os motivos que levam um dado ator social à realização da atividade; e (iii) o objeto (ou tarefa), que dirige e dá unidade a toda a atividade.

Numa conferência no PME, Saxe (1999, p. 25) define práticas como sendo "atividades recorrentes e socialmente organizadas que permeiam a vida diária". Assim, de acordo com o autor, práticas são, antes de mais, atividades (estabelecendo assim a ligação com a teoria da atividade) de carácter recorrente, isto é, realizam-se com frequência e não apenas muito esporadicamente; socialmente organizadas, ou seja, não são compreensíveis apenas pela consideração de um ator individual, mas requerem a consideração do grupo social relevante; e reconhecíveis na vida de todos os dias.

A caracterização feita por Ponte e Chapman (2006) vai numa direção semelhante, embora enfatizando um pouco mais os significados que os intervenientes atribuem ao que fazem. Para estes autores, as práticas dos professores podem ser vistas como as atividades que regularmente conduzem, tendo em atenção o contexto de trabalho e os seus significados e intenções. Deste modo, vai-se um pouco além dos motivos, introduzindo de forma mais explícita uma faceta cognitiva.

Even e Schwartz (2002) fazem também uma análise da aula através da teoria da atividade, em que analisam os motivos do professor (e também dos alunos) e as suas ações e operações. Os autores questionam-se até que ponto será possível usar diversos quadros conceptuais em simultâneo, apresentando um exemplo de uma aula que analisam segundo uma abordagem cognitiva, centrada nas interações, e segundo a teoria da atividade, centrada nos motivos dos atores. Com este exemplo inclinam-se para uma resposta negativa, mas a verdade é que é possível fazer análises micro tendo por base a Teoria da Atividade (considerando as ações e as operações) e análises macro tendo por base a abordagem cognitiva, como indica Schoenfeld (2000). Deste modo fica de pé a questão se, ao lado de quadros teóricos dificilmente compatibilizáveis (como os dois apresentados), não poderão existir outros potencialmente compatíveis.

\section{Estudos sobre as práticas profissionais dos professores de Matemática}

\subsection{Da exposição/resolução de exercícios ao questionamento/resolução de problemas}

Duas práticas de ensino reconhecíveis em muitos países (nomeadamente em Portugal), são a "exposição" e "resolução de exercícios". Estas práticas são descritas em dois artigos de Fey (1981) publicados em pleno período do back to basics que se seguiu ao movimento da Matemática moderna. $\mathrm{O}$ autor analisa os resultados de diversos inquéritos e estudos de caso sobre o ensino da Matemática nos diversos níveis de ensino. Assinala que o estilo de ensino mais comum encontrado nas escolas assume um 
primeiro momento de explicação e questionamento do professor, seguido por trabalho individual do aluno em exercícios de papel e lápis.

$\mathrm{Na}$ exposição, o professor introduz um novo tema, um novo conceito, um novo procedimento, através de uma apresentação oral, dando exemplos e, normalmente, colocando questões aos alunos. Na resolução de exercícios, os alunos praticam o que lhes foi explicado, realizando exercícios que mobilizam os conceitos e procedimentos explicados. São duas práticas distintas, que correspondem a atividades também distintas do professor e dos alunos. Para além das diferenças apresentadas, o motivo do professor também difere nos dois casos. Assim, enquanto na exposição oral o motivo do professor é a apresentação de uma nova ideia matemática aos alunos e a ação tem lugar em coletivo (desenvolvendo-se em torno do discurso dirigido pelo professor), na resolução de exercícios o motivo do professor é a interiorização e consolidação das aprendizagens dos alunos, e a ação decorre a um nível essencialmente individual (podendo registar-se alguns pedidos de esclarecimento de um ou outro aluno ao professor), que usualmente culmina com um momento de "correção" coletiva.

Cerca de 25 anos depois, na sua conferência no PME, Boaler (2003), tendo por base um amplo trabalho empírico por si conduzido, indica que as principais atividades que professores e alunos realizam na sala de aula são a discussão coletiva, o discursomonólogo do professor, o questionamento dos alunos pelo professor, o trabalho individual do aluno, a apresentação de trabalhos pelos alunos e a realização de provas de avaliação. Acrescenta ainda uma outra categoria: os alunos distraídos.

Estas atividades sugerem um conjunto de práticas de ensino que a autora considera serem reconhecíveis tanto no ensino "tradicional" como no ensino "inovador". Tendo por base os registos vídeo realizados num grande número de aulas, apresenta elementos que permitem aferir do peso que diversos tipos de atividade têm no cômputo geral do trabalho de cada professor:

Tabela 1. Diversos tipos de atividade na sala de aula

\begin{tabular}{lrc}
\hline & Aulas Tradicionais & Aulas Inovadoras \\
\hline $\begin{array}{l}\text { Exposição (os professores falam para os alunos). } \\
\text { Questionamento (os professores questionam, } \\
\text { coletivamente, os alunos). }\end{array}$ & $21 \%$ do tempo & $16 \%$ do tempo \\
$\begin{array}{l}\text { Resolução de exercícios individualmente (os } \\
\text { alunos trabalham em exercícios de resolução } \\
\text { relativamente rápida - 2,5 minutos em média). }\end{array}$ & $48 \%$ do tempo do tempo \\
$\begin{array}{l}\text { Resolução de problemas em grupo (os alunos } \\
\text { resolvem problemas de resoluçãomais demorada- } \\
6,8 \text { minutos em média). }\end{array}$ & & $32 \%$ do tempo \\
\hline
\end{tabular}

Note-se que o questionamento já aparecia, de modo secundário, associado à exposição, mas ganha aqui autonomia, subentendendo-se que se torna dominante, subordinando o eventual aspeto expositivo. Além disso, ao lado da resolução de exercícios, feita normalmente de modo individual, surge agora a resolução de problemas, feita frequentemente em grupo. 
É curioso que a percentagem temporal de questionamento coletivo dos alunos é superior em aulas inovadoras (32\% do tempo) do que em aulas tradicionais (15\%). É também interessante verificar que existem aspetos comuns aos dois tipos de ensino, nomeadamente os momentos em que professores falam para os alunos ou em que os questionam coletivamente. Isto levanta, naturalmente, a questão de saber se se trata de práticas comuns aos dois tipos de ensino, ou se pelo contrário, estando enquadradas em abordagens diferentes, devemos inferir que se trata de práticas de ensino essencialmente distintas. Já no que respeita aos momentos em que os alunos se centram na realização de tarefas, estes parecem assumir um cunho marcadamente distinto, pelos modos de trabalho implicados (individual ou em grupo) e pela natureza das tarefas envolvidas (exercícios de resolução rápida ou problemas que requerem mais tempo para se resolver). Note-se, ainda, que as percentagens de tempo acima indicadas não atingem $100 \%$, pelo que existem ainda outros tipos de atividade na sala de aula (16\% do tempo num caso e $20 \%$ no outro).

\subsection{Elementos estruturantes das práticas}

Nos comentários de Fey (1981) e na análise de Boaler (2003) há dois aspetos que se evidenciam e que discutimos de seguida: as tarefas propostas e o tipo de discurso que ocorre na sala de aula.

\subsubsection{Tarefas}

$\mathrm{Na}$ verdade, as tarefas que o professor propõe aos alunos são um elemento fundamental na definição das práticas. Faz toda a diferença propor aos alunos a resolução de exercícios de aplicação de conhecimentos já aprendidos, problemas que requerem um esforço deliberado de compreensão e a formulação de uma estratégia de resolução, ou a realização de um projeto prolongado no tempo, envolvendo a realização de um plano, recolha de dados, análise e interpretação. A importância decisiva da escolha das tarefas para a aprendizagem dos alunos é uma ideia central da educação matemática atual (National Council of Teachers of Mathematics [NCTM], 1994; Stein, Remillard, \& Smith, 2007).

As tarefas podem distinguir-se em muitos aspetos, incluindo o contexto (matemático/não matemático, familiar/não familiar), o modo de apresentação (oral, escrito, com e sem recurso a materiais) e o tempo previsível para a sua realização. Ponte (2005) propõe duas dimensões fundamentais para a análise das tarefas, a estrutura (aberta/fechada) e o grau de complexidade, e argumenta que os diferentes tipos de tarefa que daí resultam (exercício, problema, exploração, investigação) têm um papel próprio a desempenhar no processo de ensino-aprendizagem. Este autor considera que a insistência num único tipo de tarefa, o exercício, e a insuficiente atenção dada ao trabalho exploratório são razões que contribuem de forma significativa para as dificuldades de aprendizagem dos alunos.

Stein, Remillard, e Smith (2007), pelo seu lado, categorizam as tarefas em dois grandes grupos: com elevado e reduzido nível cognitivo. Chamam a atenção que, por vezes, uma tarefa é proposta a um nível cognitivo elevado mas, depois, com o decorrer do trabalho, muitas vezes devido a uma sugestão ou esclarecimento do professor, o nível cognitivo varia abruptamente, mudando completamente a natureza da tarefa e comprometendo os seus possíveis benefícios em termos de aprendizagem. Também McDonough e Clarke (2003), a partir de um estudo de professores reconhecidos pelos 
resultados dos seus alunos, propõem uma caracterização das práticas profissionais, em que as tarefas (incluindo os materiais e representações) surgem como um aspeto fundamental.

\subsubsection{Discurso}

O discurso que se desenvolve na sala de aula é outro elemento estruturante das práticas profissionais dos professores. Num discurso unívoco existe uma voz que prevalece sobre todas as demais. Em contrapartida, num discurso dialógico participam diversos interlocutores num nível de relativa igualdade. Em muitas aulas predomina de forma claramente o discurso unívoco. No entanto, Ruthven, Hofmann, e Mercer (2011) consideram que o discurso de tipo dialógico é possível em situações de ensino, levando o professor a assumir "de modo sério diferentes pontos de vista (...), encorajando os alunos a falar de modo exploratório, o que apoia o desenvolvimento da compreensão" (p. 81).

A investigação educacional há muito assinalou um tipo de discurso muito frequente nos contextos de ensino, o IRA (Iniciação-Resposta-Avaliação) (Franke, Kazemi, \& Battey, 2007). O professor começa por fazer uma pergunta (Iniciação), a que se segue uma Resposta de um aluno, que, por sua vez, dá origem a uma Avaliação do professor. Este tipo de discurso é frequentemente criticado por não deixar margem para a participação criativa dos alunos. No entanto, Ruthven, Hofmann, e Mercer (2011) sugerem que ele não é necessariamente incompatível com a fala dialógica, considerando que "promover o discurso interativo, multívoco e dialógico depende de se usar a estrutura triádica de formas particulares, tais como mudando da avaliação autoritária [no passo 3] para a promoção de mais reflexão e argumentação" (p. 82).

Um dos aspetos fundamentais do discurso é o questionamento do professor. Ponte e Serrazina (2000) sublinham em especial o papel das questões de inquirição (que admitem uma variedade de respostas legítimas), confirmação (para as quais esta sabe de antemão a resposta) e focalização (para captar a atenção de todos os alunos). Pelo seu lado, Bishop e Goffree (1986) discutem o processo de negociação de significados matemáticos e Franke, Kazemi, e Battey (2007) sublinham a importância de processos como redizer, interrogar o significado e apoiar o desenvolvimento da linguagem dos alunos.

\section{Dois exemplos de práticas profissionais}

Neste ponto discutimos duas práticas profissionais que têm sido usadas de modo cada vez mais frequentes nas aulas de Matemática, especialmente quando estas têm por base tarefas desafiantes com o objetivo de levar os alunos a envolver-se em atividade matemática: a apresentação das tarefas e as discussões coletivas.

\subsection{Apresentação das tarefas}

\subsubsection{Promover a apresentação das tarefas como prática profissional}

A apresentação das tarefas a realizar pelos alunos é um momento crítico do trabalho do professor: De que alternativas dispõe o professor? Que problemas podem surgir 
impedindo a concretização dos objetivos previstos? Como pode o professor preparar este aspeto do trabalho?

O professor escolhe uma tarefa que considera ter grande potencial educativo e, na sala de aula, apresenta-a aos alunos. Esta apresentação deve ser feita de modo que os alunos se sintam efetivamente interpelados pela tarefa e com vontade de a realizar. Como diz Skovsmose (2000), o envolvimento dos alunos na tarefa só acontece se estes aceitam o convite que lhes é feito pelo professor:

A aceitação do convite depende de sua natureza (...), depende do professor (um convite pode ser feito de muitas maneiras e para alguns alunos um convite do professor pode soar como um comando), e depende, certamente, dos alunos (no momento, eles podem ter outras prioridades). $\mathrm{O}$ que pode servir perfeitamente como um cenário para investigação para um grupo de alunos numa situação particular pode não representar um convite para um outro grupo de alunos (p. 72).

Muitas vezes a apresentação da tarefa é feita de modo mecânico e pouco envolvente. O professor, que valoriza a tarefa pois selecionou-a com cuidado, tem tendência para admitir que os alunos irão assumir uma posição idêntica à sua. No entanto, isso só acontece com aqueles que têm uma boa relação com a Matemática que, como sabemos, são uma minoria.

Uma tarefa matemática que visa o desenvolvimento do conhecimento matemático dos alunos pode conter termos que estes não conheçam ou ter um enunciado complexo que eles têm dificuldade em compreender. Torna-se, então, necessário apoiá-los na compreensão da tarefa. No entanto, se este apoio não é feito com os devidos cuidados, pode traduzir-se no abaixamento do nível cognitivo da tarefa descrito por Stein, Remillard, e Smith (2007). Sem explicar como podem os alunos resolver a tarefa, mas fazendo perguntas apropriadas, o professor pode procurarnegociar com os alunos o significado dos termos desconhecidos e levá-losa interpretar o enunciado proposto.

Deste modo, a apresentação das tarefas a realizar corresponde a uma prática profissional crítica por parte do professor, que envolve tanto um lado relacional, criando uma atmosfera propícia ao trabalho a realizar, como um lado cognitivo, representando uma oportunidade de aprendizagem e de abertura de caminhos para aprendizagens subsequentes. Trata-se de uma prática pouco estudada, a que devemos dar atenção.

\subsubsection{A tarefa "Dobras e mais Dobras"}

Esta tarefa, dos materiais de apoio ao novo Programa de Matemática para o $2 .^{\circ}$ ciclo (Menezes, Rodrigues, Tavares, \& Gomes, 2008), foi proposta na primeira aula dedicada ao estudo dos números racionais de uma turma do $5 .^{\circ}$ ano ${ }^{2}$. Os alunos já tinham estudado numerais decimais no $10^{\circ}$ ciclo, bem como operadores fracionários, usando apenas frações unitárias. A sua realização visava introduzir a linguagem associada aos números racionais em diferentes representações e significados, com os seguintes objetivos: (i) representar sob a forma de fração, numeral decimal e percentagem um número racional não negativo; (ii) compreender e usar um número racional na relação parte-todo e medida; (iii) comparar números representados de diferentes formas; e (iv) identificar e dar exemplos de frações equivalentes. A tarefa é composta por três questões, das quais referimos apenas duas (ver Figura 1):

\footnotetext{
${ }^{2}$ Apresentamos aqui apenas parte da tarefa proposta. Para mais detalhes sobre o estudo de onde este episódio foi retirado, ver Quaresma (2010).
} 
1. Encontra três tiras de papel geometricamente iguais. Dobra-as em partes iguais:

- a primeira em duas;

- a segunda em quatro;

- a terceira em oito.

Depois de dobrares cada uma das tiras, representa de diferentes formas as partes obtidas.

2. Compara as partes das três tiras obtidas por dobragem. Regista as tuas conclusões.

Figura 1. Tarefa "Dobras e mais Dobras"

A tarefa possibilita a estes alunos uma atividade exploratória a vários níveis. A questão 1 é inicialmente bastante explícita ao pedir para fazer diversas dobragens, mas faz de seguida uma solicitação que a maioria tem dificuldade em interpretar como uma indicação para usar a representação decimal, pictórica, verbal ou outra de número racional. A questão 2 pede para comparar as diversas tiras e para "tirar conclusões", o que constitui uma indicação muito aberta, suscetível de diversas indicações.

A professora organiza os alunos em grupo, formandos seis grupos com quatro ou cinco alunos cada. Distribui enunciados das questões individualmente. Os alunos mostram de imediato dificuldade na interpretação do enunciado. Deste modo, a professora promove um momento de discussão em que se negoceia a interpretação do significado dos diversos termos que embaraçam os alunos. Assim, na questão 1, recorre a um exemplo, realizando ela própria a representação da dobragem da primeira tira em duas em coletivo. Desenha a tira no quadro, representando também pictoricamente a parte da tira a considerar e pede aos alunos que digam que parte da tira está pintada. Usando a representação verbal, muitos alunos dizem que está pintada "metade da tira".

De seguida, a professora continua a insistir noutra forma de representar aquela parte e, a partir da representação verbal "metade", alguns alunos sugerem a representação decimal 0,5. A professora pede ainda outras formas de representação e dois alunos indicam a fração "um de dois", que a professora rediz como "um meio". Finalmente, como os alunos não se lembram de mais nenhuma representação, a professora pergunta: "e se eu quisesse representar em percentagem? Também podia?" Aqui a maior parte diz de imediato que é $50 \%$. Esta discussão coletiva inicial constitui uma negociação do que significa "representar", que permite a continuação do trabalho por parte dos alunos.

A resolução da questão 2 também é precedida por uma negociação do significado do trabalho a desenvolver, pois os alunos não compreendem o que é "comparar as três partes obtidas". A professora começa por mostrar as duas primeiras tiras $\left(\frac{1}{2} \mathrm{e} \frac{1}{4}\right)$ e pede aos alunos que as comparem. Alguns concluem visualmente que $\frac{1}{4}$ "é metade" de $\frac{1}{2}$ e a partir daqui todos se envolvem no trabalho.

No discurso da professora alternam-se perguntas de confirmação (para as quais esta sabe de antemão a resposta), com perguntas de focalização (para captar a atenção de todos os alunos) e de inquirição (que admitem uma variedade de respostas legítimas). No decurso deste episódio foi negociado o significado de "representar", foi ajustada a linguagem dos alunos ("um meio" como outra forma de dizer "um de dois"), e foram recordados conhecimentos dos quais os alunos estavam esquecidos (representações decimal e em percentagem). 


\subsubsection{A tarefa "Atravessando o rio"}

Esta tarefa tendo por base um problema clássico, já conhecido na Idade Média (Herbert \& Brown, 1999). Foi proposta numa turma de $7 .^{\circ}$ ano, depois de realizadas duas tarefas com sequências pictóricas, tendo em vista o início da aprendizagem da linguagem algébrica ${ }^{3}$. A sua realização visava promover nos alunos a capacidade de (i) encontrar regularidades e generalizá-las, (ii) utilizar e interpretar a linguagem algébrica, e (iii) analisar a influência da variação das condições nas soluções encontradas. Note-se que a tarefa está formulada em linguagem natural, mas a sua resolução depende de se encontrar uma representação adequada e de se interpretar os resultados matemáticos obtidos.

A consideração de um número fixo de crianças e um número variável de adultos dá origem à exploração de uma sequência (1 adulto, 2 adultos, etc.). Essa exploração tornase mais complexa com a consideração de um número variável de crianças e um número variável de adultos dando origem a uma família de sequências. A realização da tarefa envolve diversos momentos de apresentação/negociação, trabalho autónomo dos alunos (aos pares) e discussão coletiva, encerrando com uma síntese final.

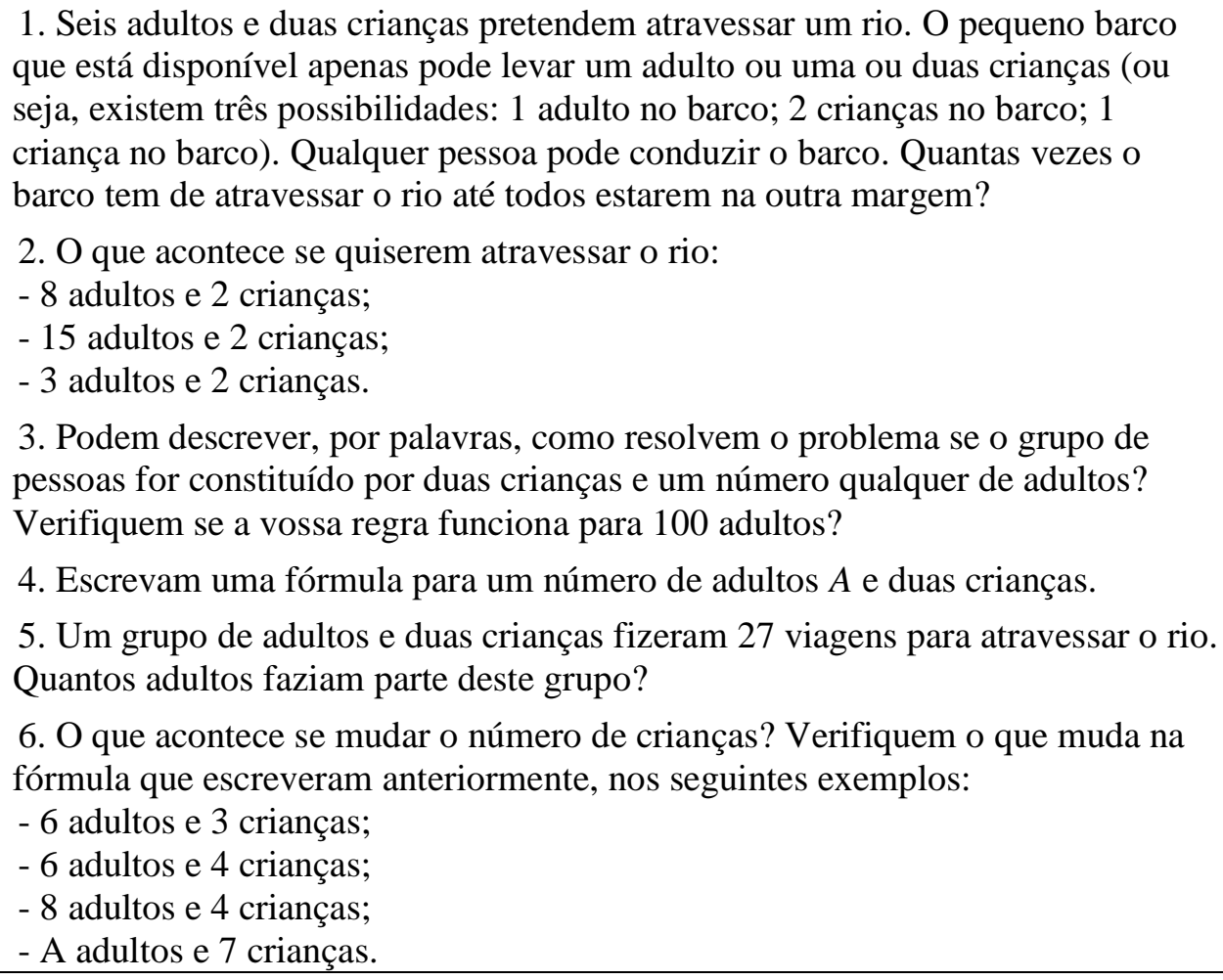

1. Seis adultos e duas crianças pretendem atravessar um rio. $O$ pequeno barco que está disponível apenas pode levar um adulto ou uma ou duas crianças (ou seja, existem três possibilidades: 1 adulto no barco; 2 crianças no barco; 1 criança no barco). Qualquer pessoa pode conduzir o barco. Quantas vezes o barco tem de atravessar o rio até todos estarem na outra margem?

2. $\mathrm{O}$ que acontece se quiserem atravessar o rio:

- 8 adultos e 2 crianças;

- 15 adultos e 2 crianças;

- 3 adultos e 2 crianças.

3. Podem descrever, por palavras, como resolvem o problema se o grupo de pessoas for constituído por duas crianças e um número qualquer de adultos? Verifiquem se a vossa regra funciona para 100 adultos?

4. Escrevam uma fórmula para um número de adultos $A$ e duas crianças.

5. Um grupo de adultos e duas crianças fizeram 27 viagens para atravessar o rio. Quantos adultos faziam parte deste grupo?

6. O que acontece se mudar o número de crianças? Verifiquem o que muda na fórmula que escreveram anteriormente, nos seguintes exemplos:

- 6 adultos e 3 crianças;

- 6 adultos e 4 crianças;

- 8 adultos e 4 crianças;

- A adultos e 7 crianças.

Figura 2. Tarefa "Atravessando o rio"

A professora pede aos alunos para discutirem entre si a situação e formularem estratégias de resolução. Apresenta a tarefa, salientando as condições dadas para as viagens. Os alunos começam a trabalhar, simulando as primeiras viagens e discutindo várias possibilidades. Contudo, a situação revela-se confusa e os alunos colocam

\footnotetext{
${ }^{3}$ Para mais detalhes sobre o estudo de onde este episódio foi retirado, ver Branco (2008).
} 
questões à professora para esclarecer as condições dadas e para discutir as suas conjeturas. Gera-se um ambiente de alguma agitação.

Neste ponto a professora considera necessário um momento de diálogo coletivo que ajude os alunos a compreender e interiorizar as condições da situação proposta. Seguindo a sugestão de um par de alunos, solicita a atenção de toda a turma para as viagens que se realizam e pergunta o que acontece se na primeira viagem o barco for conduzido por um adulto:

Professora: Explica Xico.

Xico: O barco ia levar um adulto e depois vinha. O barco só podia levar um adulto de cada vez. Como eram $6 \ldots 6$ vezes 2 , fica 12. E na última volta podia levar as duas crianças, era só mais uma vez.

Professora: Como é a primeira viagem que ele faz? Quem é que vai lá dentro, Xico?

Xico: Um adulto.

Professora: E como é que o barco volta para trás?

Xico: Vem sozinho.

Professora: Não pode. Tem de haver alguém a conduzir o barco. Meninos [Chama a atenção de toda a turma]. Na primeira pergunta temos 6 adultos e 2 crianças. $O$ barco vai de uma margem para outra e têm de pensar quem vai dentro de barco de modo que haja alguém que o conduza para trás. Ou não? Diz [Diana].

Diana: Um adulto vai levar duas crianças.

Professora: Mas no mesmo barco, ao mesmo tempo, vai um adulto e duas crianças? Se for um adulto dentro do barco não pode ir mais ninguém com ele. Só podem ir, ou duas crianças, ou uma sozinha, ou um adulto. Não cabe mais ninguém. Ricardo.

Ricardo: Vão duas crianças para lá e depois vem uma para cá buscar outra criança.

Professora: Só há duas crianças. Vão pensar com calma. Continuem e encontrem um modo de fazer.

Tal como no episódio anterior, também aqui a discussão inicial é essencial para o trabalho que se segue. Num primeiro momento, a professora solicita a um aluno que apresente a sua estratégia de resolução, sabendo de antemão que esta não é viável. Depois, através de perguntas cuidadosamente formuladas, procura que os alunos compreendam as condições da situação proposta e analisem criticamente a viabilidade da estratégia que formularam. Assim, os alunos verificam a necessidade de a primeira viagem ser realizada por duas crianças de modo a permitir que o barco regresse à margem de partida, sendo novamente conduzido por uma criança. Posto isso, a professora questiona quem pode seguir no barco nas viagens seguintes e remete os alunos para o trabalho autónomo.

\subsection{Discussões coletivas}

\subsubsection{Promover discussões coletivas como prática profissional}

A discussão coletiva é um momento da aula que tem vindo a merecer grande atenção por parte dos educadores matemáticos. Para perceber o seu lugar nas práticas dos professores é preciso responder a questões como: Para que servem estas discussões? Em que circunstâncias são pertinentes? Em que circunstâncias são efetivamente 
promotoras de aprendizagem? Que fatores podem levar ao seu empobrecimento? Como podem ser preparadas e conduzidas pelo professor de modo a otimizar o seu alcance educativo?

Por exemplo, Ruthven, Hofmann, e Mercer (2011) centram a sua atenção nos momentos de discussão coletiva que têm lugar depois da realização de uma tarefa em pequenos grupos. Mostram como uma sequência de abertura dá origem a vários pontos de vista na turma, que são depois expressos de modo mais detalhado. Indicam que "as intervenções da professora servem predominantemente para apoiar os alunos na sua articulação do pensamento matemático e para levar estrategicamente a turma a relacionar esse pensamento a exemplos, ou princípios, ou ferramentas já previamente encontrados" (p. 87). Referem que as contribuições sucessivas de vários alunos não conduzem a uma formulação persuasiva do ponto de vista matemático convencional, o que leva a professora a entrar na discussão apresentando uma representação preparada de antemão e que lhe parece poder apoiar uma discussão produtiva. A introdução desta representação origina contribuições dos alunos que permitem à professora reverter para a sua posição distanciada usual. E os autores sublinham que, nas sequências iniciadas pelos alunos, as intervenções da professora servem predominantemente para promover, redizer e dinamizar as contribuições dos alunos, bem como para dirigir o curso da discussão.

Stein, Engle, Smith, e Hughes (2008) referem que nestas discussões, muitas vezes, os alunos se limitam a apresentar, à vez, a sua estratégia de resolução do problema proposto. Sublinham a importância do professor selecionar as ideias matemáticas que cada estratégia pode ilustrar, estabelecer conexões entre diferentes métodos de solução ligando-os a métodos importantes em Matemática, e analisar as estratégias que possam ser mais úteis e eficientes em certas situações. Deste modo, descrevem o que designam por cinco práticas específicas para promover a produtividade de discussões matemáticas: antecipar as respostas matemáticas dos alunos, monitorizar estas respostas, selecionar e sequenciar criteriosamente respostas para apresentação na turma, e estabelecer conexões entre as respostas dos alunos. As autoras ilustram todos estes aspetos e mostram como elas podem ser um importante recurso no trabalho do professor.

Deste modo, as discussões coletivas, especialmente se têm por base o trabalho já previamente feito pelos alunos, constituem uma importante oportunidade de aprendizagem. Para que essa oportunidade seja efetivamente aproveitada, é preciso saber o que elas implicam em termos do trabalho do professor.

\subsubsection{A tarefa "Dobras e mais Dobras".}

No início da discussão coletiva da questão 1 a professora pede a cada grupo que afixe o seu trabalho no quadro e pede ao primeiro grupo que o apresente à turma (Figura 3):

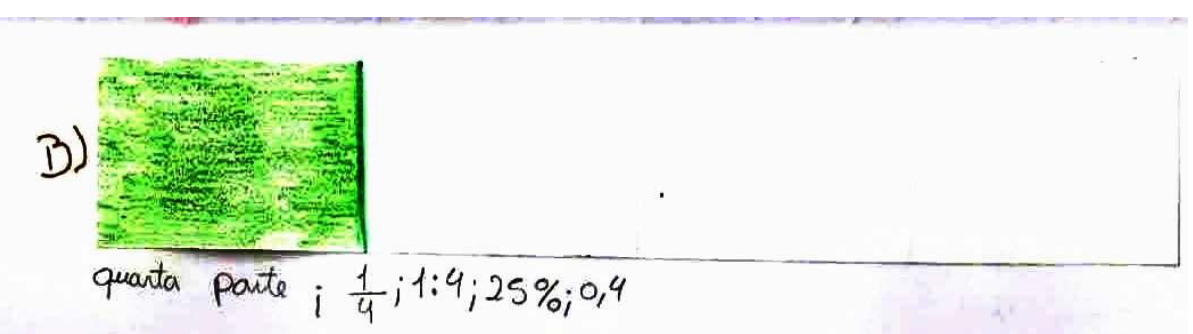

Figura 3. Resposta de Carolina, Diana e Filipe, Questão 1b) 
Professora: Sim [Diana], vens explicar aquilo que o teu grupo fez. (...) Alto, mais alto para os outros ouvirem.

Diana: Na figura B escrevemos: quarta-parte; 1 por $4\left[\frac{1}{4}\right] ; 1$ a dividir por $4 ; 25 \%$ e 0,4 .

Professora: Estiveram com atenção? Concordam com aquilo que a Diana disse?

Turma: Sim...

Os alunos não se apercebem do erro da colega quando refere que o número decimal que representa a situação é 0,4 . A professora decide que retomará a questão mais tarde e prossegue para a apresentação do grupode Tiago (Figura 4):

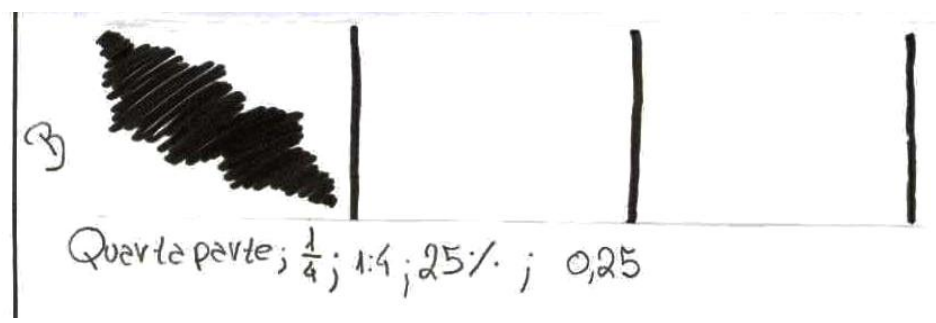

Figura 4. Resposta de Tiago, Leonor, Rui e Henrique na Questão 1b)

Tiago: Então nós temos: quarta-parte; um sobre quatro [-1]4; um a dividir por quatro; $25 \% \mathrm{e}$ 0,25 .

Professora: (...) Concordas Diana?

Diana: Sim...?

Turma: Não! Está mal...

Professora: O que é que está mal?

Rui: É o $0,25 \ldots$

Professora: Porquê?

Rui: Porque é a quarta-parte.

Daniel: É 0,25 porque é a metade do primeiro. O primeiro era 50, se fizermos a metade é 25.

André: Oh professora! Eu acho que é o 0,25 porque é a quarta-parte do 100. Porque 25 vezes 4 dá 100 .

A interpelação direta da professora a Diana assinala que há algo que precisa de atenção. A aluna fica confusa e são os colegas que acabam por esclarecer a situação. Note-se como, a seguir à pergunta "porquê?" da professora, diversos alunos apresentam explicações sucessivamente mais refinadas. É de notar que nos seis grupos existentes apenas o de Diana comete o erro de "transformar" o denominador da fração em numeral decimal, tendo os restantes grupos obtido a sua resposta por comparação com o valor anterior e com $100 \%$. 
$\mathrm{Na}$ terceira tira, todos os grupos usam corretamente a representação verbal, a fração, o quociente e a percentagem. Contudo, todos os alunos mostram dificuldades na representação em numeral decimal. Verificam-se dois tipos de erros. Um, como vimos, surge no grupo de Diana que constrói o numeral decimal por transformação do denominador da fração. Outro erro, cometido por alguns grupos, tem origem na dificuldade em determinar a metade de 0,25 . Os alunos começam por determinar metade de $25 \%$ e conseguem chegar a 12,5 , só que, depois, mostram dificuldade em obter metade de 0,25. Sabem que $\frac{1}{4}$ é 0,25 , mas, ao fazerem a metade de 0,25 , escrevem 12,5. É o caso do grupo de Tiago:

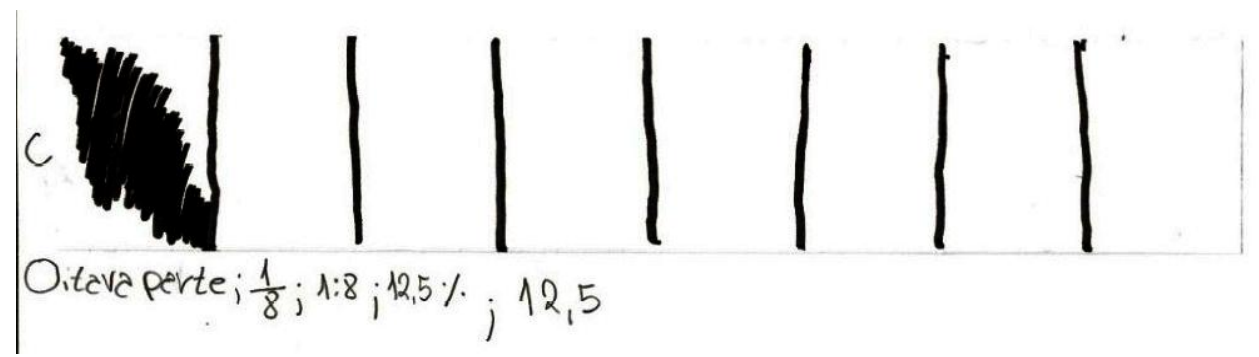

Figura 5. Resposta de Leonor, Rui, Henrique e Tiago na Questão 1c)

Contudo, durante a discussão da tarefa, os alunos indicam a resposta correta:

Daniel: É $12,5 \%$ porque a $c$ é metade da $b$.

Professora: Se o $b$ era 25\%, o $c$ é...

Daniel: É a metade que é 12.

Professora: É 12\%?

Luís: Não professora é 12,5\%. Porque 12,5+12,5 é 25.

Professora: Então e o decimal, como é que fica?

Tiago: É 0,125 .

(...)

André: Pois é 0,125.

Professora: Porquê?

André: É 0,125 porque 0,125 x 8 é que dá uma unidade inteira.

É o próprio Tiago quem chega à resposta correta, mas depois é André que a justifica estabelecendo a relação com a unidade. Registem-se as questões por parte da professora, tanto de confirmação como de inquirição ("porquê?")

$\mathrm{Na}$ questão 2, todos os grupos estabelecem diversas relações entre as partes mas só alguns conseguem comparar todas as tiras. Todos os grupos usam apenas a linguagem verbal para exprimir essas relações. Eis um exemplo (Figura 6): 
2. Compara as partes das três tiras obtidas por dobragem. Regista as tuas conclusões.

$$
\begin{aligned}
& \text { A 1-a é dabra da } 2-a \\
& \text { A } 2^{\circ} \text { é a metade da } 1^{-a} \text {. } \\
& \text { A 3á metadeda } 2-a \\
& \text { A 2" a doba da } 3^{-a} \\
& \text { A1 }{ }^{a} \text { i a quadraplo daza. } \\
& \text { A } 3^{\circ} \text { é a quato parte do } 1-a
\end{aligned}
$$

Figura 6. Resposta de Mariana, Elsa, Alexandre e Leonardo na Questão 2

André e os colegas, para além das relações simples, "metade" e "dobro", estabeleceram relações mais complexas de "quádruplo" (tendo por base "dobro" do "dobro") e "quarta parte" ("quarta metade" no dizer de um deles, para significar "metade de metade"). Na discussão desta questão a professora pede a cada grupo que indique uma das relações que encontrou. Como os alunos só usam a representação verbal, durante a discussão, pede-lhes que usem também a linguagem matemática:

Daniel: A relação entre o primeiro e o segundo, é que o segundo é metade do primeiro.

Professora: Como é que eu posso escrever isso utilizando números? Como é que eu faço a metade?

André: Dividir por 2.

Rui: Um de quatro é igual a metade a dividir por 2.

André: A $b$ é o dobro da $c$.

Professora: Como é que eu escrevo isso?

André: Um de quatro é o dobro.

Professora: Como é que é o dobro?

André: Duas vezes...

Professora: Duas vezes o quê?

André: Um traço oito.

Professora: Um oitavo. Um quarto é o dobro de um oitavo.

Alexandre: $\mathrm{O}$ primeiro é o dobro do segundo.

Professora: Como é que eu escrevo isso?

Alexandre: Um meio é o dobro de... Um sobre quatro.

É de notar como a professora intervém, redizendo a intervenção de André ("um oitavo"), ajudando-o, bem como a toda a turma, a desenvolver a sua linguagem matemática. 
Apesar das dificuldades apresentadas, os alunos encontram diversas relações entre $\frac{1}{2}, \frac{1}{4} \mathrm{e} \frac{1}{8}$ usando, essencialmente, representações pictóricas. Conseguem, autonomamente, comparar as três frações apresentadas, o que os ajuda bastante na compreensão dos números racionais, especialmente no que respeita ao significado parte-todo e à compreensão da magnitude de um número racional. Exprimem essas relações em linguagem verbal mas mostram dificuldades em representá-las utilizando a linguagem matemática. Como esta foi a primeira aula de ensino formal deste tópico, é natural que os alunos ainda tenham bastantes dificuldades com a linguagem própria das frações.

Note-se o estilo de questionamento da professora, pontuado por questões de inquirição ("vens explicar...", “o que é que está mal?", "porquê?”...). Assinale-se, também, o seu cuidado em ajudar os alunos a desenvolver a sua linguagem matemática, redizendo as suas intervenções. Finalmente, registe-se como a cultura da sala de aula já integrou a noção que os alunos podem contribuir com diferentes respostas e discordar e argumentar uns com os outros.

\subsubsection{A tarefa "Atravessando o rio"}

Quando a maioria dos alunos termina a questão 2, a professora promove um momento de discussão coletiva para aferir a sua compreensão da situação e confrontar as suas diferentes representações. Os vários pares de alunos usam diferentes representações. Alguns descrevem em linguagem natural todas as viagens, outros produzem esquemas ou associam representações icónicas e simbólicas (Figuras 7 e 8). Algumas representações possibilitam rapidamente a identificação da regularidade.

No caso de oito adultos e duas crianças, Susana revela um raciocínio já bastante abstrato, que apresenta no quadro, escrevendo $8 \times 4+1=33$, cujo significado explica do seguinte modo:

Susana: Fazemos oito adultos vezes o número de viagens que eles têm de fazer para levarem um adulto para a margem e fazemos mais um que é o número que as crianças fazem de volta.

Durante a discussão da questão 3, Susana apresenta uma regra para determinar o número total de viagensque usa para o caso de 100 viagens, indicando a expressão $100 \times 4+1=401$ :

Susana: Então, é assim: Vai ser o número de adultos vezes as quatro viagens mais uma viagem das crianças.

Professora: Está certo.

Susana: Nos cem adultos fica cem vezes quatro mais um que é igual a quatrocentos e um. 


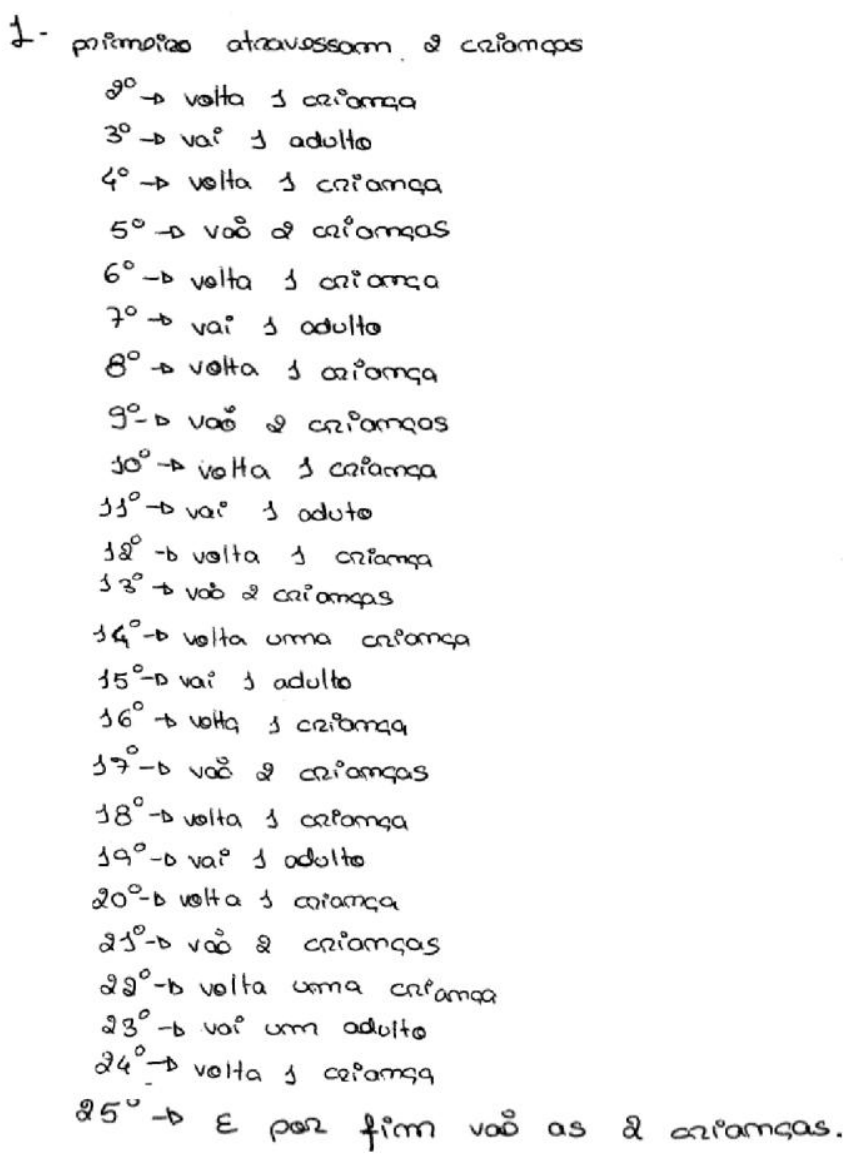

Figura 7. Representação de Beatriz e Andreia na Questão 1

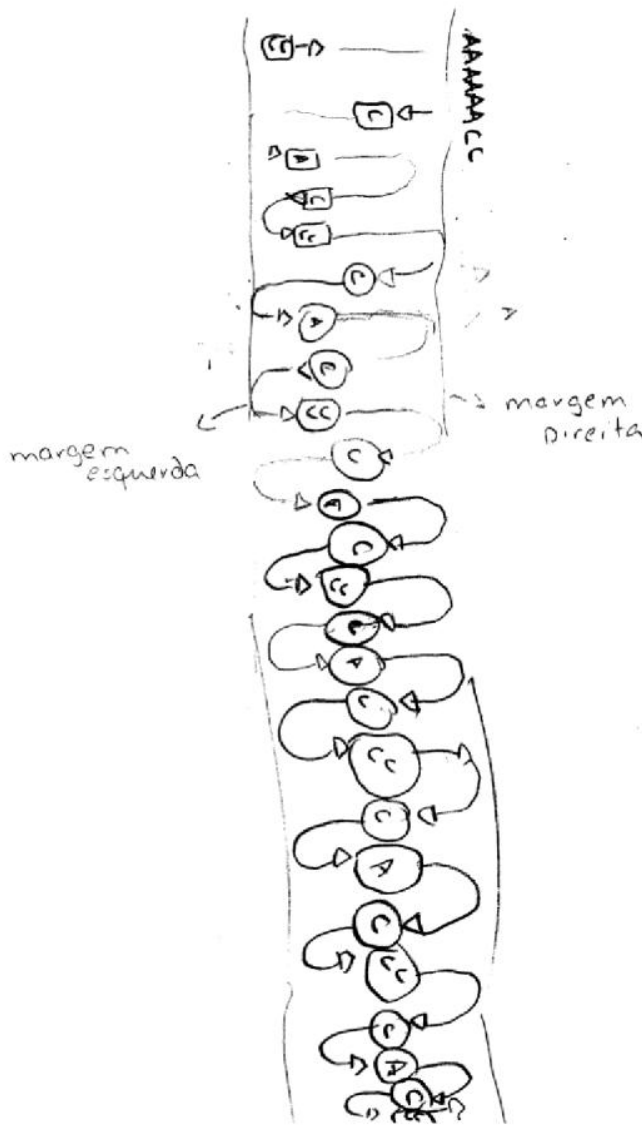

Figura 8. Representação de Joana e Catarina na Questão 1

$\mathrm{Na}$ discussão da questão 4, os alunos apresentam várias expressões algébricas, como $A \times 4+1,4 \times A+1$ e $4 A+1$, o que permite discutir a utilização da propriedade comutativa na multiplicação e a omissão do sinal " $\times$ ":

Professora: Se o número de adultos for representado pela letra $A$, como é que fica?

Betânia: $A$ vezes 4 mais um [a aluna está escreve a expressão no quadro].

(...)

Professora: Há uma outra maneira, simplificada, de escrevermos a fórmula?

Andreia: $A 4$ mais 1.

Batista: 4 A mais 1.

Professora: $O$ Batista diz que pode ser $4 A$ mais 1 [a professora escreve a expressão no quadro $4 A+1$ ]. Porque é que pode ser como $4 \mathrm{~A}$ ?

Andreia: Tiramos o vezes.

Professora: E a multiplicação é comutativa.

Discute-se, ainda, o significado dos termos e coeficientes. Verificam que o coeficiente 4 representa a sequência de quatro viagens que se repete, o termo $4 A$ indica o número de viagens necessário para que $A$ adultos mudem de margem e o termo 1 
representa a última viagem, realizada pelas duas crianças. Na sequência, a professora questiona como se pode calcular o número de viagens para diferentes números de adultos, utilizando a expressão algébrica, explorando o significado dos termos e coeficientes e, desse modo, desenvolvendo a linguagem dos alunos:

Professora: Se $A$ for igual a vinte e seis o que é que significa?

Joana: Que há vinte e seis adultos.

Professora: Se $A$ é igual a vinte e seis, digo que há vinte e seis adultos. Como é que devo fazer?

Susana: É o vinte e seis vezes quatro mais um.

Na questão 5 é dado um número de viagens e os alunos devem determinar o número de adultos que integram o grupo, sem que os adultos repitam viagens. Os alunos sugerem a realização das operações inversas, contudo, alguns têm dificuldade em decidir qual a operação a realizar em primeiro lugar. Vários usam uma abordagem aritmética, o que é natural dado que ainda não iniciaram o estudo das equações. Começam por dividir vinte e sete por quatro mas verificam que assim não faz sentido retirar em seguida a última viagem. No momento da discussão, Joana intervém:

Joana: Não dá certo.

Professora: Não dá?

Joana: Não dá certo. A 27 retira-se 1 e depois divide-se por 4.

Professora: E o que é que acontece?

Joana: Dá 6,5.

Professora: O que é que significa?

Paulo: Não é número certo [referindo-se a número natural].

As questões de inquirição da professora promovem a interpretação do resultado matemático obtido, tendo em conta o contexto da situação. A questão 6 introduz uma variante no número de crianças, sendo necessário estudar a influência desta condição na regra encontrada anteriormente. Os alunos são chamados a explorar a influência da variação do número de crianças na necessidade de viagens. Verificam que não se altera o conjunto de quatro viagens que é necessário fazer para que um adulto mude de margem. Com duas crianças, além do conjunto de quatro viagens por cada adulto, realiza-se uma viagem final para transportar uma criança. Com três crianças verificam que apenas o número de viagens se altera no final, sendo necessário realizar mais duas viagens para transportar a terceira criança. Tendo mais duas, ou seja, quatro crianças no total, fazem duas viagens por cada criança, ou seja, duas vezes duas viagens. Respondem a cada uma das situações com base em esquemas relativos a casos particulares. Durante a discussão, a professora, desta vez com um questionamento mais dirigido, procura ajudá-los a formular a generalização:

Professora: Quando tenho duas crianças é isto aqui $[8 \times 4+1]$. Faltam-me quantas crianças?

Batista: Duas.

Professora: E quantas viagens tenho de fazer para as ir buscar?

Susana: Mais quatro. 
Professora: Cada vez que vou buscar mais uma criança são duas viagens [conclusão das alíneas anteriores]. Se forem oito adultos e quatro crianças... Diz, Xico.

Xico: Oito vezes quatro mais um mais quatro.

Professora: E agora, se tiver $A$ adultos e 7 crianças? [Ninguém responde] Para duas crianças a expressão é esta $[4 A+1]$. Mas agora não tenho duas, tenho mais quantas?

Andreia: Cinco.

Professora: Vou ter mais cinco. Quantas viagens é que tenho de fazer por cada uma delas?

Diana: Duas.

Andreia: Cinco vezes dois.

Professora: Então, fica quanto? Como é que simplifico a expressão?

Susana: Quatro A mais...

Diana: Dois vezes cinco dá dez.

Batista: Onze.

Na discussão desta última questão os alunos analisam a influência da alteração do número de crianças na expressão obtida. Verificam que a sequência de quatro viagens necessária para colocar um adulto na outra margem se mantém e que, para além da viagem realizada no final pelas duas crianças, se fazem duas viagens por cada criança a mais. Deste modo, identificam uma nova regularidade que respeita ao número de crianças (Figura 9).

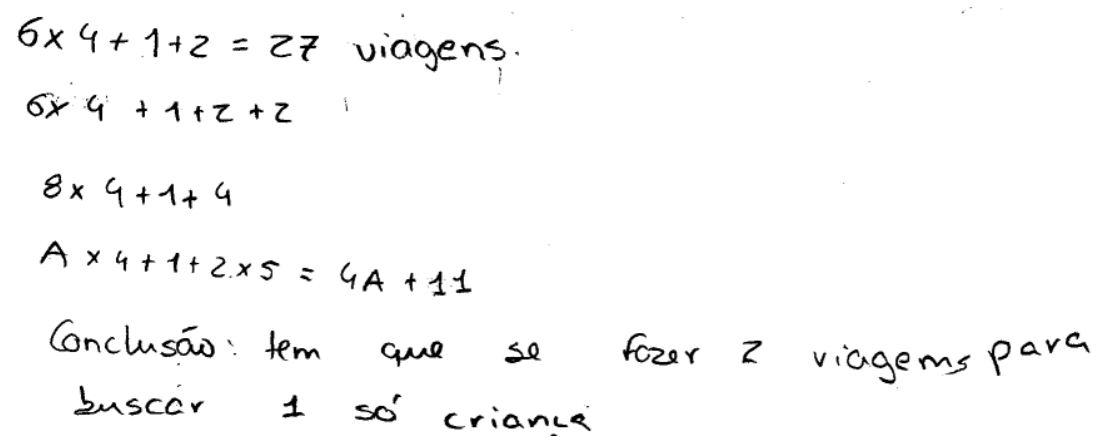

Figura 9. Resposta de Joana e Catarina após a discussão na Questão 6

A apresentação das resoluções dos alunos cria oportunidades para a negociação do significado de conceitos como "termos" e "coeficientes" e para a análise das regras da escrita simbólica, nomeadamente no que respeita à multiplicação. Permite também a comparação de representações icónicas e simbólicas, numéricas e algébricas, bem como a análise da equivalência de diferentes expressões algébricas. O modo como a professor conduz a discussão permite aos alunos compreenderem a situação segundo diferentes perspetivas, esclarecerem significados e perceberem a importância do uso de representações eficientes, criando também condições para fazerem generalizações envolvendo uma dupla variação (no número de adultos e no número de crianças). 


\section{Conclusão}

Este artigo discute a noção de prática profissional, apresentando exemplos de duas práticas que assumem grande importância no trabalho do professor. As perspetivas teóricas que apresentámos sobre as práticas profissionais levam-nos a pensar que não existe incompatibilidade intransponível entre as abordagens de cunho cognitivista e de cunho sociocultural. Na nossa perspetiva, no estudo das práticas profissionais do professor de Matemática é preciso ter em atenção diversos aspetos:

1. Os motivos do professor, o modo como estes originam os objetivos que pretende alcançar e como são concretizados através de diversas ações profissionais. Como referimos, no momento de introdução da tarefa é fundamental conseguir o envolvimento dos alunos e garantir que eles dispõem do conhecimento necessário para a realizar; nas discussões coletivas, é necessário criar oportunidades para evidenciar conceitos, representações, procedimentos matemáticos e suas conexões e para promover o desenvolvimento de capacidades transversais como o raciocínio e a comunicação.

2. O contexto social e o contexto educativo, nos quais têm um lugar de destaque as orientações curriculares, tanto as oficiais como as que são assumidas na escola onde o professor trabalha, sendo preciso dar especial atenção ao modo como o professor interpreta e se relaciona com essas orientações.

3. O contexto da turma, sendo particularmente importante o interesse que os alunos pela Matemática, o modo como se envolvem no trabalho, a relação que assumem com o professor e a margem de desenvolvimento da cultura da sala de aula.

4. O conhecimento profissional do professor, nos seus diversos domínios, incluindo a Matemática, o currículo, os processos de aprendizagem, a Didática da Matemática e a sua capacidade de localizar e construir recursos para o ensino-aprendizagem.

5. O saber-fazer do professor, que se traduz na capacidade de realizar de modo eficaz as ações e operações necessárias à concretização de cada prática.

6. A capacidade reflexiva do professor, base da sua aprendizagem e melhoria do desempenho profissional.

Nos exemplos apresentados neste artigo as professoras assumem as orientações no novo programa de Matemática do ensino básico (Ministério da Educação [ME], 2007), que traduz uma perspetiva inovadora do ensino desta disciplina, com o qual se identificam totalmente. Ambas as turmas têm um desempenho em Matemática mediano, mas os alunos dão uma resposta positiva às propostas de trabalho apresentadas, mostrando interesse em aprender e assumindo uma cultura de participação no discurso da sala de aula. A experiência ainda limitada de ambas as professoras (uma no segundo outra no quinto ano de serviço) é compensada pelo trabalho detalhado de preparação das aulas descritas e o facto de se tratar de experiências de ensino feitas no quadro de trabalhos de investigação proporciona um enquadramento muito forte para a reflexão e análise do trabalho realizado.

Os estudos sobre as práticas profissionais do professor de Matemática têm proporcionado uma quantidade impressionante de informação. No entanto, nem sempre estes estudos têm atendido aos aspetos acima indicados, limitando muitas vezes o seu alcance e o seu possível impacto como conhecimento útil à sociedade e aos atores educativos. Muitos deles focam-se em práticas de nível geral, contrastando as grandes orientações curriculares "tradicionais" e "inovadoras". Trata-se, no entanto, de 
categorias muito gerais e sujeitas a uma grande variedade de interpretações. Outros estudos situam-se sobretudo ao nível das ações e operações do professor, tornando difícil de perceber o enquadramento subjacente. Por isso, consideramos importante prosseguir o estudo de práticas profissionais de nível intermédio, como as analisadas neste artigo, procurando documentá-las, mostrando a sua exequibilidade e a sua relação com aprendizagens significativas dos alunos.

\section{Referências}

Bishop, A., \& Goffree, F. (1986). Classroom organization and dynamics. Em B. Christiansen, A. G. Howson \& M. Otte (Eds.), Perspectives on mathematics education (pp. 309-365). Dordrecht, The Netherlands: D. Reidel.

Boaler, J. (2003). Studying and capturing the complexity of practice: The case of the 'dance of agency'. Em N. Pateman, B. Dougherty, \& J. Zilliox (Eds.), Proceedings of the 27th Conference of the International Group for the Psychology of Mathematics Education (Vol. 1, pp. 3-16). Honolulu, HI: PME.

Branco, N. (2008). O estudo de padrões e regularidades no desenvolvimento do pensamento algébrico (Dissertação de mestrado). Universidade de Lisboa, Lisboa, Portugal. Disponível em http://repositorio.ul.pt/.

Fey, J. T. (1981). Mathematics teaching today: Perspectives from three national surveys. Reston, VA: NCTM.

Franke, M. L., Kazemi, E., \& Battey, D. (2007). Understanding teaching and classroom practice in mathematics. Em F. Lester (Ed.), Second handbook of mathematics teaching and learning (pp. 225-256). Greenwich, CT: Information Age Publishing.

Even, R., \& Schwartz, B. B. (2002). Implications of competing interpretations of practice and research and theory in mathematics education. Em A. D. Cockburn, \& E. Nardi (Eds.), Proceedings of the 26th Conference of the International Group for the Psychology of Mathematics Education (Vol. 2, pp. 337-344). Norwich, UK: PME.

Herbert, K., \& Brown, R. (1999). Patterns as tools for algebraic reasoning. Em B. Moses (Ed.), Algebraic thinking, grades $K-12$ (pp. 123-128). Reston, VA: NCTM.

Leinhardt, G. (1988). Expertise in instructional lessons: An example from fractions. Em D. Grouws, T. Cooney, \& D. Jones (Eds.), Perspectives of research on effective mathematics teaching (pp. 47-66). Reston, VA: NCTM e LEA.

McDonough, A., \& Clarke, D. (2003). Describing the practice of effective teachers of mathematics in the early years. Em N. Pateman, B. Dougherty, \& J. Zilliox (Eds.), Proceedings of the 27th Conference of the International Group for the Psychology of Mathematics Education (Vol. 3, pp. 261-268). Honolulu, HI: PME.

Menezes, L., Rodrigues, C., Tavares, F., \& Gomes, H. (2008). Números racionais não negativos: Tarefas para $5^{\circ}$ ano (Materiais de apoio ao professor). Lisboa, Portugal: DGIDC. Disponível em http://www.esev.ipv.pt/mat1ciclo/Publicacoes\%20DGIdc1.htm

Ministério da Educação (2007). Programa de Matemática do Ensino Básico. Lisboa, Portugal Disponível em http://area.dgidc.minedu.pt/materiais_NPMEB/028_ProgramaMatematicaEnsinoBasico.pdf

National Council of Teachers of Mathematics (1994). Normas profissionais para o ensino da Matemática. Lisboa, Portugal: IIE e APM.

Ponte, J. P. (2005). Gestão curricular em Matemática. Em GTI (Ed.), O professor e o desenvolvimento curricular (pp. 11-34). Lisboa, Portugal: APM. 
Ponte, J. P., \& Chapman, O. (2006). Mathematics teachers' knowledge and practices. Em A. Gutierrez, \& P. Boero (Eds.), Handbook of research on the psychology of mathematics education: Past, present and future (pp. 461-494). Roterdham: The Netherlands: Sense.

Ponte, J. P., \& Serrazina, L. (2000). Didáctica da Matemática para o $1 .^{\circ}$ ciclo do ensino básico. Lisboa, Portugal: Universidade Aberta.

Quaresma, M. (2010). Ordenação e comparação de números racionais em diferentes representações: uma experiência de ensino (Dissertação de mestrado). Universidade de Lisboa, Lisboa, Portugal. Disponível em http://repositorio. ul. pt/.

Ruthven, K., Hofmann, R., \& Mercer, N. (2011). A dialogic approach to plenary problem synthesis. Em B. Ubuz (Ed.), Proceedings of the 35th Conference of the International Group for the Psychology of Mathematics Education (Vol. 4, pp. 81-88). Ankara, Turkey: PME.

Sánchez, M. (2011). A review of research trends in mathematics teacher education. PNA - Revista de Investigación en Didáctica de la Matemática, 5(4), 129-145.

Saxe, G. B. (1999). Professional development, classroom practices, and students' mathematics learning: A cultural perspective. Em O. Zaslavsky (Ed.), Proceedings of the 23th Conference of the International Group for the Psychology of Mathematics Education (Vol. 3, pp. 121-128). Haiffa, Israel: PME.

Schoenfeld, A. (2000). Models of the teaching process. Journal of Mathematical Behavior, $18(3), 243-261$.

Shulman, L. S. (1986). Those who understand: Knowledge growth in teaching. Educational Researcher, 15(2), 4-14.

Skovsmose, O. (2000). Cenários para investigação. Bolema, 14, 66-91.

Stein, M. K., Engle, R. A., Smith, M., \& Hughes, E. K. (2008). Orchestrating productive mathematical discussions: Five practices for helping teachers move beyond show and tell. Mathematical Thinking and Learning, 10, 313-340.

Stein, M. K., Remillard, J., \& Smith, M. (2007). How curriculum influences student learning. Em F. Lester (Ed.), Second handbook of mathematics teaching and learning (pp. 319-369). Greenwich, CT: Information Age.

\section{Referencias a los autores:}

João Pedro da Ponte. Instituto de Educação da Universidade de Lisboa (Portugal). jpponte@ie.ul.pt

Marisa Quaresma. Escola Básica 2,3 José Saramago, Poceirão, Palmela e Unidade de Investigação do Instituto de Educação da Universidade de Lisboa (Portugal). marisa-quaresma@hotmail.com

Neusa Branco. Escola Superior de Educação de Santarém e Unidade de Investigação do Instituto de Educação da Universidade de Lisboa (Portugal). neusacvbranco@gmail.com 